Cite this: Phys. Chem. Chem. Phys., 2011, 13, 6610-6618

\title{
Structural evidence of anomeric effects in the anesthetic isoflurane $\dagger$
}

\author{
Alberto Lesarri, ${ }^{a}$ Alicia Vega-Toribio, ${ }^{a}$ Richard D. Suenram, ${ }^{b}$ Dale J. Brugh, ${ }^{c}$ \\ Davood Nori-Shargh, $\ddagger^{d}$ James E. Boggs ${ }^{d}$ and Jens-Uwe Grabow ${ }^{e}$
}

Received 9th November 2010, Accepted 8th February 2011

DOI: $10.1039 / \mathrm{c0cp02465a}$

The conformational and structural properties of the inhalational anesthetic isoflurane (1-chloro-2,2,2-trifluoroethyl difluoromethyl ether) have been probed in a supersonic jet expansion using Fourier-transform microwave (FT-MW) spectroscopy. Two conformers of the isolated molecule were identified from the rotational spectrum of the parent and several ${ }^{37} \mathrm{Cl}$ and ${ }^{13} \mathrm{C}$ isotopologues detected in natural abundance. The two most stable structures of isoflurane are characterized by an anti carbon skeleton $\left(\tau\left(\mathrm{C}_{1}-\mathrm{C}_{2}-\mathrm{O}-\mathrm{C}_{3}\right)=137.8(11)^{\circ}\right.$ or $\left.167.4(19)^{\circ}\right)$, differing in the trans (AT) or gauche (AG) orientation of the difluoromethyl group. The conformational abundances in the jet were estimated from relative intensity measurements as $(\mathrm{AT}) /(\mathrm{AG}) \approx 3: 1$. The structural preferences of the molecule have been rationalized with supporting $a b$ initio calculations and natural-bond-orbital (NBO) analysis, which suggest that the molecule is stabilized by hyperconjugative effects. The NBO analysis of donor-acceptor ( $\mathrm{LP} \rightarrow \sigma^{*}$ ) interactions showed that these stereoelectronic effects decrease from the AT to AG conformations, so the conformational preferences can be accounted for in terms of the generalized anomeric effect.

\section{Introduction}

Many different compounds are able to induce anesthesia. However, the molecular mechanisms of general anesthetics continue a subject of debate not totally understood. While most evidence suggests that anesthetic action would involve interaction with multiple receptor sites interfering with synaptic transmission, ${ }^{1,2}$ full-scale experimental descriptions of anesthetic binding to membrane proteins are not presently achievable,$^{3}$ so anesthetic mechanisms are usually ascertained using large-scale molecular modelling. ${ }^{4}$ In consequence, the experimental description of the conformational preferences

\footnotetext{
${ }^{a}$ Departamento de Química Física y Química Inorgánica, Facultad de Ciencias, Universidad de Valladolid, E-47011 Valladolid, Spain.

E-mail: lesarri@qf.uva.es; Web: http://www.uva.es/lesarri;

Fax: + 34 983-423013

${ }^{b}$ Department of Chemistry, University of Virginia, Charlottesville, VA 22904, USA

${ }^{c}$ Department of Chemistry, Ohio Wesleyan University, Delaware, OH 43015, USA

${ }^{d}$ Institute for Theoretical Chemistry, Department of Chemistry, University of Texas, Austin, TX 78712, USA

${ }^{e}$ Institut für Physikalische Chemie \& Elektrochemie, Lehrgebiet A, Gottfried-Wilhelm-Leibniz Universität Hannover, D-30167 Hannover, Germany

$\dagger$ Electronic supplementary information (ESI) available: Tables of rotational frequencies for the observed conformations and isotopologues, substitution coordinates and additional ab initio data. See DOI: $10.1039 / \mathrm{c} 0 \mathrm{cp} 02465 \mathrm{a}$

$\ddagger$ Permanent address: Chemistry Department, Science and Research Campus, Islamic Azad University, Tehran, Iran.
}

and molecular structure of different classes of anesthetics is of general interest for the understanding of the intermolecular interactions and docking mechanisms between anesthetics and protein receptors controlling biological action.

This report is the second in a series dedicated to the molecular properties and structure of the inhalational anesthetics, a family of compounds comprising several multihalogenated ethyl methyl and ethyl isopropyl ethers. The first study was devoted to sevoflurane, ${ }^{5}$ which is now followed by the investigation of isoflurane (1-chloro-2,2,2-trifluoroethyl difluoromethyl ether). A microwave study of the phenolic anesthetic propofol was also published recently. ${ }^{6}$ Isoflurane is an example of stereoselective action in haloethers, with the dextrorotatory isomer reported 1.5-2 times more effective than the levo species. ${ }^{7}$ Actually, the stereospecific interaction of isoflurane enantiomers has been used as an argument to support the interaction with neuronal ion channels and the role of protein binding in the central nervous system. Isoflurane is reported to act on a variety of molecular targets, binding to GABA, glutamate and glycine receptors, and also inhibiting conduction in activated potassium channels. ${ }^{2}$

There are some previous structural studies of isoflurane in condensed phases using vibrational circular dichroism (VCD) ${ }^{8}$ and crystal X-ray diffraction. ${ }^{9}$ The low-resolution $\left(4 \mathrm{~cm}^{-1}\right)$ VCD study suggested the presence of at least two conformations at room temperature and established the absolute configuration of the dextrorotatory molecule as $(+)-(S)$-isoflurane. These authors investigated also the molecular conformation using 
Hartree-Fock ab initio calculations, but the reported population ratio $(50: 50)$ differed considerably from the theoretical predictions (ca. $85: 15$ ). The chiroptical assignment was confirmed by the latter X-ray diffraction experiment, but only a single conformation was detected in crystalline isoflurane. A more recent gas electron diffraction (GED) experiment ${ }^{10}$ conducted more elaborated density-functional theory (DFT) and MP2 ab initio calculations and was interpreted in terms of the two conformations of the VCD study in population ratios of 83(11)/17(11).

Our present study was thus originated by five reasons: (a) the lack of high-resolution spectroscopic studies which could offer accurate information on the rotational and hyperfine parameters for all populated conformations of the isolated molecule, free of crystal, matrix or solvent effects. (b) The troubles of GED experiments in the case of multiconformational systems and its inability to resolve simultaneously the structures of different conformations, as illustrated by the fact that for isoflurane only the structure of the most stable conformer could be determined. (c) The need to assess the structural results of GED, which were based on a fit of the diffraction pattern to a combination of determinable and assumed structural parameters, difficult when finding multiple similar bonds, like the $\mathrm{C}-\mathrm{O}$ or $\mathrm{C}-\mathrm{F}$ bonds of isoflurane. (d) The contradictory information of the available molecular orbital calculations on the number and relative stability of the conformations of this molecule. (e) Finally, our interest to establish the role of anomeric effects on the molecular conformation, previously proposed qualitatively from the GED data. $^{10}$

Unlike the aforementioned experimental methods the rotational spectrum is unique in providing a distinct spectral signature for each conformer or even isotopologue present in a polar gaseous sample. In consequence the analysis of the rotational spectrum provides an accurate description of the intrinsic conformation and structure of the free molecule that can be used as an experimental benchmark for the $a b$ initio and large-scale molecular mechanics calculations used in anesthetic modeling.

\section{Experimental and computational methods}

\section{a Experimental methods}

The rotational spectrum of isoflurane was analyzed in a jet-cooled expansion. Isoflurane $(97 \%)$ was obtained from a commercial source and used without further purification. The sample is an easily vaporizable liquid (bp $48-49{ }^{\circ} \mathrm{C}$ ), so it was prepared as a diluted $(\sim 0.5 \%)$ gas mixture in an inert carrier gas (pure $\mathrm{Ne}$ or $\mathrm{Ne} / \mathrm{He} 80 / 20$ ). The expansion of the initial mixture (stagnation pressures of 1-2 bar) through a pulsed solenoid valve $(\varnothing=0.8 \mathrm{~mm})$ generated the supersonic jet in the evacuated expansion chamber, which was probed using microwave spectroscopy.

The rotational spectrum was recorded using two Fouriertransform microwave (FT-MW) spectrometers at NIST and Hannover, operating between 8-26 GHz. The initial measurements and the spectral assignments of the most stable conformer started at $\mathrm{NIST}^{11}$ (Gaithersburg, MD) and were continued for the minor conformer and isotopic species with the instrument in Hannover. ${ }^{12}$ Both spectrometers are based on automated and improved versions of the original BalleFlygare $^{13}$ design, using a coaxial arrangement of the jet and the resonator axes (COBRA) $)^{12}$ for increased sensitivity. In this technique a series of microwave pulses applied within a Fabry-Pérot resonator are used to achieve a molecular polarization of the molecules in the expanding jet. The subsequent transient spontaneous emission or free-induced decay is downconverted from microwave to radiofrequencies and digitized in the time-domain. Finally the frequency domain spectrum displaying the resonant frequencies of the rotational transitions is reconstructed with a Fourier transformation. The coaxial propagation of the microwaves and jet expansion doubles all experimental frequencies by the Doppler effect, so the rest frequencies are calculated from the averaged doublet. The accuracy of the frequency measurements is better than $3 \mathrm{kHz}$. Transitions separated by $6 \mathrm{kHz}$ are resolvable.

\section{b Computations}

The computational study used several methods implemented in Gaussian03. ${ }^{14}$ Similarly to our previous work on sevoflurane we compared the results of the Møller-Plesset second-order perturbation theory (MP2) in the frozen-core approximation and DFT theory using Becke's B3LYP hybrid functional. A triple- $\zeta 6-311++\mathrm{G}(2 \mathrm{df}, \mathrm{p})$ basis set, which was found dependable in our study of sevoflurane, was used in combination with the two molecular methods. A NBO analysis was additionally carried out on the two most stable conformations of the molecules, using density functional theory (B3LYP/ $\left.6-311++\mathrm{G}^{* *}\right)$. In these calculations the stabilization energy $\left(E_{2}\right)$ associated with $i \rightarrow j$ delocalization is explicitly estimated by the following equation:

$$
E_{2}=q_{i} \frac{F^{2}(i, j)}{\varepsilon_{j}-\varepsilon_{i}}
$$

where $q_{i}$ is the $i$ th donor orbital occupancy, $\varepsilon_{i}, \varepsilon_{j}$ are diagonal elements (orbital energies) and $F(i, j)$ off-diagonal elements, respectively, associated with the NBO Fock matrix. Therefore, there is a direct relationship between $F(i, j)$ off-diagonal elements and the orbital overlap $(S)$. The stereoelectronic orbital interactions are anticipated to be more effective for the anti rather than the syn or gauche arrangement between the donor and acceptor orbitals, and the stabilization should increase as the acceptor orbital energy decreases and the donor orbital energy increases.

\section{Results}

\section{a Rotational spectrum}

A survey scan of isoflurane in the microwave region of 12-14 $\mathrm{GHz}$ is shown in Fig. 1. The spectrum was dominated by the $R$-branch $(J+1 \leftarrow J) \mu_{a}$-transitions of a near-prolate asymmetric rotor, denoted conformer 1 . All transitions appeared split into several hyperfine components with relatively broad separations $(<4 \mathrm{MHz})$ typical of the nuclear quadrupole effects originated by a ${ }^{35} \mathrm{Cl}$ nucleus, coupling the nuclear spin angular momentum $(I=3 / 2)$ with the molecular rotation 


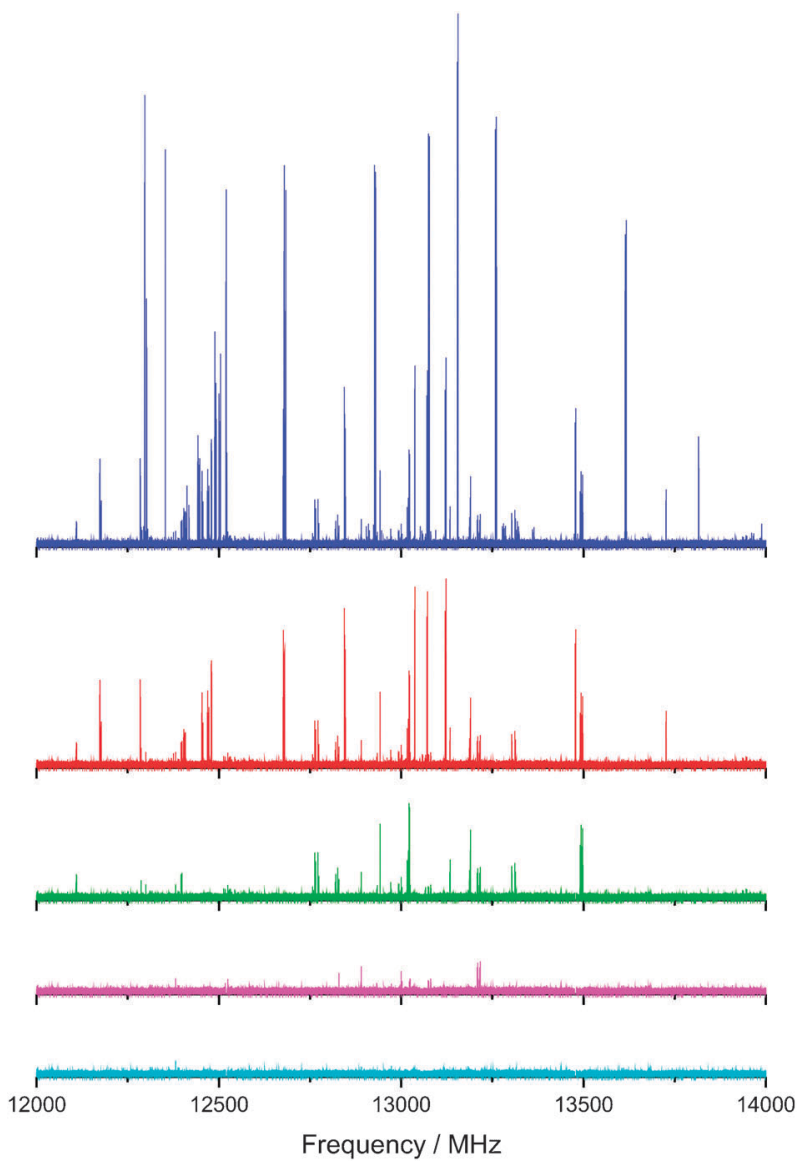

Fig. 1 A $2 \mathrm{GHz}$ section of the microwave spectrum of isoflurane (upper trace). The spectra in the lower traces have been obtained after removing sequentially the lines from conformer $1\left({ }^{35} \mathrm{Cl}\right.$ and $\left.{ }^{37} \mathrm{Cl}\right)$ and conformer $2\left({ }^{35} \mathrm{Cl}\right.$ and $\left.{ }^{37} \mathrm{Cl}\right)$. No additional conformers are noticeable in the remaining spectrum shown as lowest trace.

$(\boldsymbol{F}=\boldsymbol{I}+\boldsymbol{J}) \cdot{ }^{15} \mathrm{~A}$ smaller set of $R$-branch transitions with $\mu_{b}$ and $\mu_{c}$ selection rules could also be measured, but these were typically much weaker, as observed in Fig. 2. Tunnelling doublings due to internal rotation of the terminal trifluoromethyl group were not detected. The analysis of the spectrum thus used a Watson semirigid-rotor Hamiltonian ${ }^{16,17}$ supplemented with a nuclear quadrupole coupling term, and resulted in the rotational parameters of Table 1. The determinable parameters included the rotational and all quartic centrifugal distortion constants, together with the diagonal elements of the nuclear quadrupole coupling tensor $\chi_{\alpha \alpha}(\alpha=a, b, c)$, related to the molecular electric field gradient at the quadrupolar nucleus $(\boldsymbol{q})$ according to $\chi=e Q \boldsymbol{q}(Q$ being the nuclear electric quadrupole moment). ${ }^{15}$

The assignment of the most abundant conformer was extended to the monosubstituted isotopologues in natural abundance. We assigned initially the rotational spectrum of the ${ }^{37} \mathrm{Cl}$ species, which is notorious in Fig. 1 because of its large relative abundance $(24.2 \%)$. The derived rotational parameters in Table 1 show smaller nuclear quadrupole coupling constants, as expected from the ratio of nuclear quadrupole momenta $Q\left({ }^{35} \mathrm{Cl}\right) / Q\left({ }^{37} \mathrm{Cl}\right)=1.26878(15) .{ }^{15}$ The assignment of the weaker ${ }^{13} \mathrm{C}$ species $(1.1 \%)$ was accomplished for the carbon atoms in the trifluoro and difluoromethyl

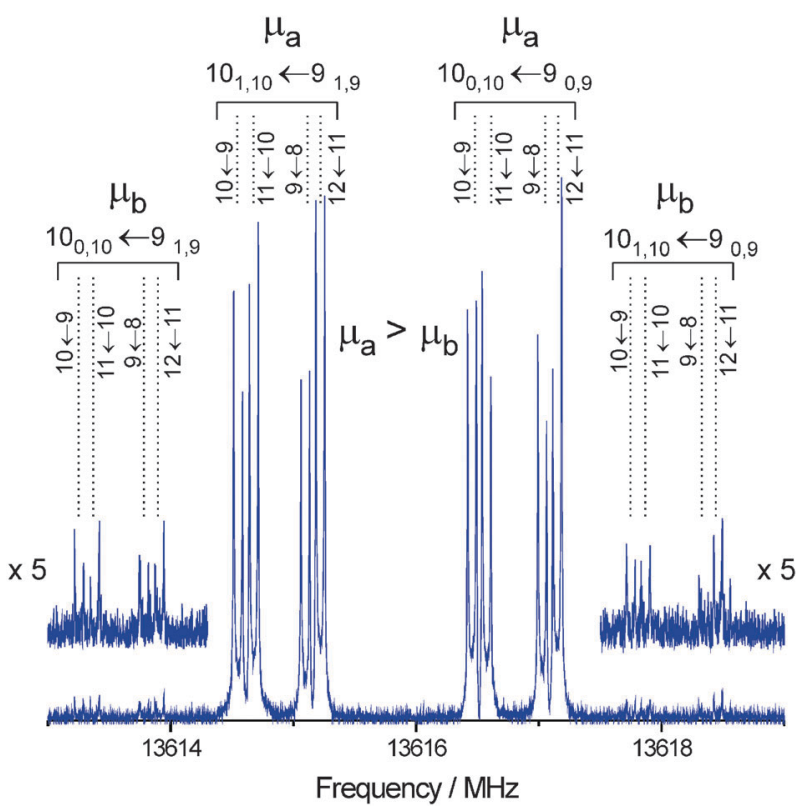

Fig. 2 The nuclear quadrupole coupling hyperfine splittings in isoflurane illustrated with four $\mu_{a}$ and $\mu_{b}$ rotational transitions (quantum numbers $J^{\prime} K^{\prime}-1, K^{\prime}+1 \leftarrow J^{\prime \prime} K^{\prime \prime}-1, K^{\prime \prime}+1$ ) for the most abundant conformer (hyperfine components labeled $F^{\prime} \leftarrow F^{\prime \prime}$ ). Each component appears as a doublet because of the instrumental Doppler effect.

groups $\left({ }^{13} \mathrm{C}_{1}\right.$ and ${ }^{13} \mathrm{C}_{3}$ in Table 1$)$. The study of the remaining ${ }^{13} \mathrm{C}_{2}$ species was not possible because of the proximity of this atom to the center of mass, resulting in partial overlapping with the parent species. Transitions originated by the ${ }^{18} \mathrm{O}$ isotopologue $(0.2 \%)$ were too weak and undetectable since the intensity is further divided into several hyperfine components.

Once conformer 1 was excluded from the spectrum a number of weaker unassigned transitions were still apparent, as observed in the third trace of Fig. 1. Attempts to assign this spectrum on the basis of the $\mu_{a}$ transitions were unsuccessful. However, a pattern of 16 hyperfine components near $13.5 \mathrm{GHz}$ in Fig. 3 could be recognized as a symmetric quartet originated by two external $\mu_{b}$ and two weaker $\mu_{c}$ rotational transitions, ${ }^{18}$ each split into four hyperfine components. On this assignment a new set of $R$-branch transitions from a second asymmetric rotor denoted conformer 2 was measured, including a few $\mu_{a}$ lines. The analysis of the spectrum was similar to that of conformer 1 and produced the rotational parameters shown in Table 2.

For the weaker conformer 2 it was possible to identify the ${ }^{37} \mathrm{Cl}$ species in natural abundance, but transitions originated from the ${ }^{13} \mathrm{C}$ or ${ }^{18} \mathrm{O}$ species could not be detected for intensity reasons. No additional conformers were detected after removing conformer 2 from the spectrum, as observed in the lowest trace of Fig. 1. The full set of measured transitions for the two conformers is given as ESI $\dagger$ (Tables S1-S6).

Information on the conformational populations in the jet was derived from the relative intensities of the microwave transitions. ${ }^{19}$ This calculation assumes that the jet expansion has frozen the full population to the vibrational ground states of each conformational well. Line intensities were compared for $\mu_{b}$ selection rules only because of the larger magnitude of this component for the weaker conformer. A calculation using 
Table 1 Rotational parameters of the most abundant conformer of isoflurane

\begin{tabular}{lllll}
\hline & Conformer 1 & ${ }^{37} \mathrm{Cl}$ & ${ }^{13} \mathrm{C}_{1}$ & ${ }^{13} \mathrm{C}_{3}$ \\
\hline$A^{a} / \mathrm{MHz}$ & $1569.03462(23)^{c}$ & $1531.9103(14)$ & $1567.89612(72)$ & $1567.27020(86)$ \\
$B / \mathrm{MHz}$ & $876.13130(12)$ & $875.74403(33)$ & $873.236176(75)$ & $869.331824(79)$ \\
$C / \mathrm{MHz}$ & $658.486625(98)$ & $651.665830(83)$ & $656.641837(30)$ & $654.626164(37)$ \\
& & & & 0.09324 \\
$\Delta_{\mathrm{J}} / \mathrm{kHz}$ & $0.09324(44)$ & $0.0864(13)$ & 0.0582 & 0.09324 \\
$\Delta_{\mathrm{JK}} / \mathrm{kHz}$ & $0.0582(27)$ & $0.0752(50)$ & 0.3236 & 0.0582 \\
$\Delta_{\mathrm{K}} / \mathrm{kHz}$ & $0.3236(84)$ & 0.3236 & 0.03450 & 0.3236 \\
$\delta_{\mathrm{J}} / \mathrm{kHz}$ & $0.03450(29)$ & $0.03180(81)$ & 0.2091 & 0.2091 \\
$\delta_{\mathrm{K}} / \mathrm{kHz}$ & $0.2091(50)$ & $0.1957(63)$ & 35.981 & 35.981 \\
$\chi_{a a} / \mathrm{MHz}$ & $35.981(15)$ & $28.231(11)$ & -73.84 & -73.84 \\
$\chi_{b b} / \mathrm{MHz}$ & $-73.84(2)$ & $-58.040(15)$ & 37.86 & 37.86 \\
$\chi_{c c} / \mathrm{MHz}$ & $37.86(2)$ & $29.809(15)$ & 41 & 40 \\
$N^{b}$ & 111 & 40 & 1.6 & 1.9 \\
$\sigma / \mathrm{kHz}$ & 2.2 & 0.9 & &
\end{tabular}

${ }^{a}$ Rotational constants $(A, B, C)$, Watson's A-reduction quartic centrifugal distortion constants $\left(\Delta_{\mathrm{J}}, \Delta_{\mathrm{JK}}, \Delta_{\mathrm{K}}, \delta_{\mathrm{J}}, \delta_{\mathrm{K}}\right)$ and nuclear quadrupole coupling tensor elements $\left(\chi_{\alpha \beta}, \alpha, \beta=a, b, c\right) .{ }^{b}$ Number of transitions $(N)$ and rms deviation of the fit $(\sigma) .{ }^{c}$ Standard error in parentheses in units of the last digit. Parameters without errors were fixed at the values of the parent species.

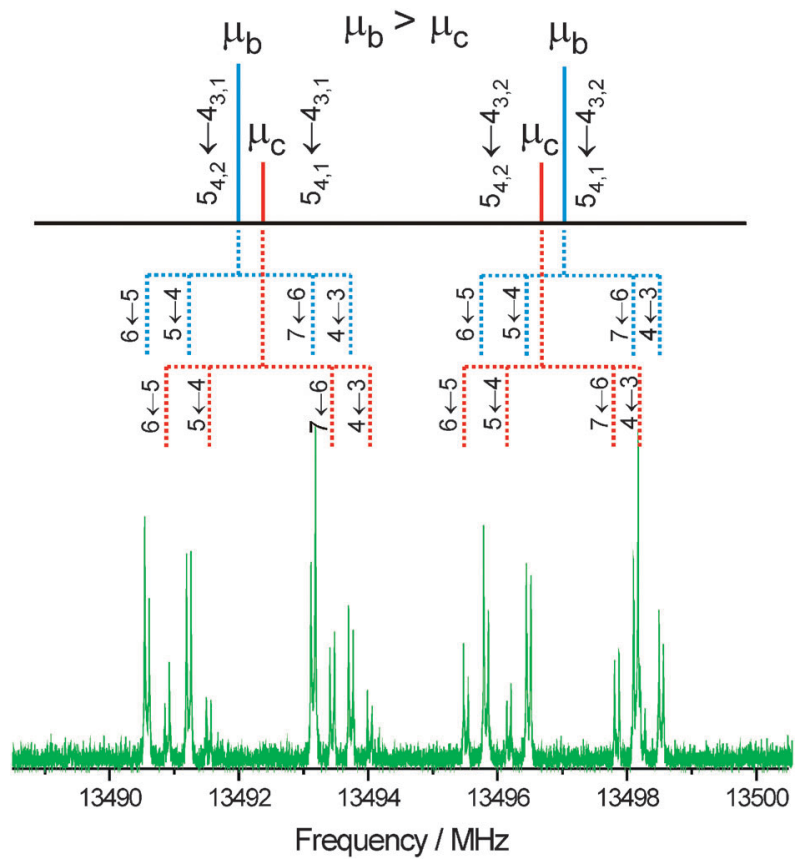

Fig. 3 Assignment of the second conformer of isoflurane on the basis of a $\mu_{b}-\mu_{c}$ symmetric quartet (quantum numbers $J^{\prime} K^{\prime}-1, K^{\prime}+1 \leftarrow$ $J^{\prime \prime}{ }_{K^{\prime \prime}-1, K^{\prime \prime}+1}, F^{\prime} \leftarrow F^{\prime \prime}$.

seven rotational transitions and the theoretical electric dipole moment components in Table 3 yielded a conformational ratio of $N_{1} / N_{2} \approx 3.2(1.1)$ under optimum $\pi / 2$ polarization conditions.

\section{b PES and conformational assignment}

The presence of two conformers in the jet-cooled rotational spectrum of isoflurane was rationalized with the help of the potential energy surface (PES) shown in Fig. 4 (B3LYP/ $6-311++\mathrm{G}(2 \mathrm{df}, \mathrm{p}))$. Three low-energy basins are apparent in the PES, denoted AT, AG and Ag. In the three cases the molecule adopts a similar orientation for the $\mathrm{C}_{1}-\mathrm{C}_{2}-\mathrm{O}-\mathrm{C}_{3}$
Table 2 Rotational parameters of the second stable conformation of isoflurane

\begin{tabular}{lll}
\hline & Conformer 2 & ${ }^{37} \mathrm{Cl}$ \\
\hline$A^{a} / \mathrm{MHz}$ & $1630.8870(12)$ & $1591.98346(19)$ \\
$B / \mathrm{MHz}$ & $751.128775(98)$ & $750.66558(13)$ \\
$C / \mathrm{MHz}$ & $631.72101(17)$ & $625.475912(68)$ \\
& & \\
$\Delta_{\mathrm{J}} / \mathrm{kHz}$ & 0.000 & 0.000 \\
$\Delta_{\mathrm{JK}} / \mathrm{kHz}$ & $0.334(16)$ & 0.334 \\
$\Delta_{\mathrm{K}} / \mathrm{kHz}$ & $0.050(31)$ & 0.050 \\
$\delta_{\mathrm{J}} / \mathrm{kHz}$ & 0.000 & 0.000 \\
$\delta_{\mathrm{K}} / \mathrm{kHz}$ & $-0.425(21)$ & -0.425 \\
& & \\
$\chi_{a a} / \mathrm{MHz}$ & $33.263(29)$ & $26.129(37)$ \\
$\chi_{b b} / \mathrm{MHz}$ & $-65.567(29)$ & $-51.660(39)$ \\
$\chi_{c c} / \mathrm{MHz}$ & $32.303(29)$ & $25.532(39)$ \\
$N$ & 69 & 32 \\
$\sigma / \mathrm{kHz}$ & 4.8 & 4.3
\end{tabular}

${ }^{a}$ Parameters defined as in Table 1. Parameters without errors were fixed at the values of the parent species.

skeleton (Fig. 5 for notation), indicating that the anti (A) orientation of the chlorine atom and the trifluoromethyl group is always the most stable conformation. The three minima differ in the orientations of the difluoromethyl group, defined by the $\mathrm{C}_{2}-\mathrm{O}-\mathrm{C}_{3}-\mathrm{H}$ dihedral. In the predicted global minimum AT the hydrogen atom in the difluoromethyl group is trans (T) with respect to the ether plane. A rotation of $c a . \pm 120^{\circ}$ of this group produces two unequivalent conformations, with the hydrogen atom gauche, either to the same side (AG, second most stable) or opposite side (Ag) of the chlorine atom. A section of the PES along the $\mathrm{C}_{2}-\mathrm{O}-\mathrm{C}_{3}-\mathrm{H}$ relaxation pathway is also presented, showing the closer relative energies between conformers AT and AG and the larger energy separation with conformer Ag. In order to predict the molecular parameters relevant to the interpretation of the rotational spectrum the three structures in Fig. 4 were fully reoptimized using $\mathrm{MP} 2 / 6-311++\mathrm{G}(2 \mathrm{df}, \mathrm{p})$. In this model the global minimum AT corresponds to a $\left(\mathrm{C}_{1}-\mathrm{C}_{2}-\mathrm{O}-\mathrm{C}_{3}\right)$ dihedral of $138^{\circ}$, 
Table 3 Ab initio rotational parameters of isoflurane

\begin{tabular}{|c|c|c|c|}
\hline & \multicolumn{3}{|l|}{${\text { Ab } \text { initio }^{a}}$} \\
\hline & $\begin{array}{l}\text { Conformer } \\
\text { AT }\end{array}$ & $\begin{array}{l}\text { Conformer } \\
\text { AG }\end{array}$ & $\begin{array}{l}\text { Conformer } \\
\mathrm{Ag}\end{array}$ \\
\hline$\overline{A^{b} / \mathrm{MHz}}$ & 1573.7 & 1633.6 & 1670.9 \\
\hline$B / \mathrm{MHz}$ & 882.9 & 756.3 & 782.3 \\
\hline$C / \mathrm{MHz}$ & 663.5 & 636.2 & 598.3 \\
\hline$\Delta_{\mathrm{J}} / \mathrm{kHz}$ & 0.092 & 0.025 & 0.033 \\
\hline$\Delta_{\mathrm{JK}} / \mathrm{kHz}$ & 0.040 & 0.28 & 0.28 \\
\hline$\Delta_{\mathrm{K}} / \mathrm{kHz}$ & 0.313 & -0.021 & 0.065 \\
\hline$\delta_{\mathrm{J}} / \mathrm{kHz}$ & 0.034 & 0.006 & 0.0035 \\
\hline$\delta_{\mathrm{K}} / \mathrm{kHz}$ & 0.196 & -0.254 & 0.099 \\
\hline$\chi_{a a} / \mathrm{MHz}$ & 33.6 & 30.9 & 34.5 \\
\hline$\chi_{b b} / \mathrm{MHz}$ & -68.9 & -61.2 & -63.4 \\
\hline$\chi_{c c} / \mathrm{MHz}$ & 35.2 & 30.4 & 28.9 \\
\hline$\chi_{a b} / \mathrm{MHz}$ & 14.6 & 13.5 & 6.1 \\
\hline$\chi_{a c} / \mathrm{MHz}$ & -0.2 & 2.4 & -1.1 \\
\hline$\chi_{b c} / \mathrm{MHz}$ & -7.19 & -23.7 & 26.5 \\
\hline$\left|\mu_{a}\right| / \mathrm{D}$ & 1.48 & 0.56 & 0.24 \\
\hline$\left|\mu_{b}\right| / \mathrm{D}$ & 0.31 & 1.61 & 0.06 \\
\hline$\left|\mu_{c}\right| / \mathrm{D}$ & 0.25 & 0.95 & 2.60 \\
\hline $\mid \mu_{\text {total }} / / \mathrm{D}$ & 1.53 & 1.95 & 2.62 \\
\hline$\Delta(E+\mathrm{ZPE})^{c} / \mathrm{kJ} \mathrm{mol}^{-1}$ & 0 & 1.9 & 9.2 \\
\hline$\Delta G / \mathrm{kJ} \mathrm{mol}^{-1}$ & 0 & 1.8 & 6.3 \\
\hline
\end{tabular}

considerably smaller than in conformers AG $\left(168^{\circ}\right)$ and $\mathrm{Ag}$ $\left(153^{\circ}\right)$. The orientation of the difluoromethoxy group is defined by $\left(\mathrm{C}_{2}-\mathrm{O}-\mathrm{C}_{3}-\mathrm{H}\right)$ torsions of $177^{\circ}(\mathrm{AT}), 59^{\circ}$ (AG) and $-40^{\circ}(\mathrm{Ag})$. The calculated rotational and centrifugal distortion constants, nuclear quadrupole coupling tensor, electric dipole moments and relative electronic and free energies of the three structures are collected in Table 3 .

The comparison between the experimental and predicted rotational parameters in Tables 1-3 provided an unequivocal conformational assignment of conformers 1 and 2 as isoflurane $\mathrm{AT}$ and AG, respectively. The prediction of the rotational constants overestimates the experimental values in all cases, but the global agreement is very good (relative differences below $0.8 \%$ in $B$ and $C$ and $0.3 \%$ in $A$ ). The nuclear quadrupole coupling constants have been recognized also as a very useful tool to discriminate between close molecular geometries, ${ }^{20}$ as illustrated here by the large differences predicted between conformers AG and Ag. For conformers AT and AG the magnitude of the predicted nuclear quadrupole coupling constants differs several $\mathrm{MHz}$ from the experimental values, but the relative variations between the observed conformers are reproduced quite well by the predictions, offering no doubt on the conformational assignments. The magnitude of the predicted electric dipole moment components agrees also qualitatively with the observed spectra. In conformer AT $\mu_{a}$ ( $=1.5 \mathrm{D})$ is much larger than $\mu_{b}$ and $\mu_{c}(\sim 0.3 \mathrm{D})$. Conversely, $\mu_{b}(=1.6 \mathrm{D})$ is dominant in conformer $\mathrm{AG}\left(\mu_{c}=1.0>\mu_{a}=\right.$ $0.6 \mathrm{D})$, as observed. Finally the predicted quartic centrifugal distortion constants for conformer AT are also in very good agreement with those observed for conformer 1. For conformer 2 not all constants were determined experimentally.

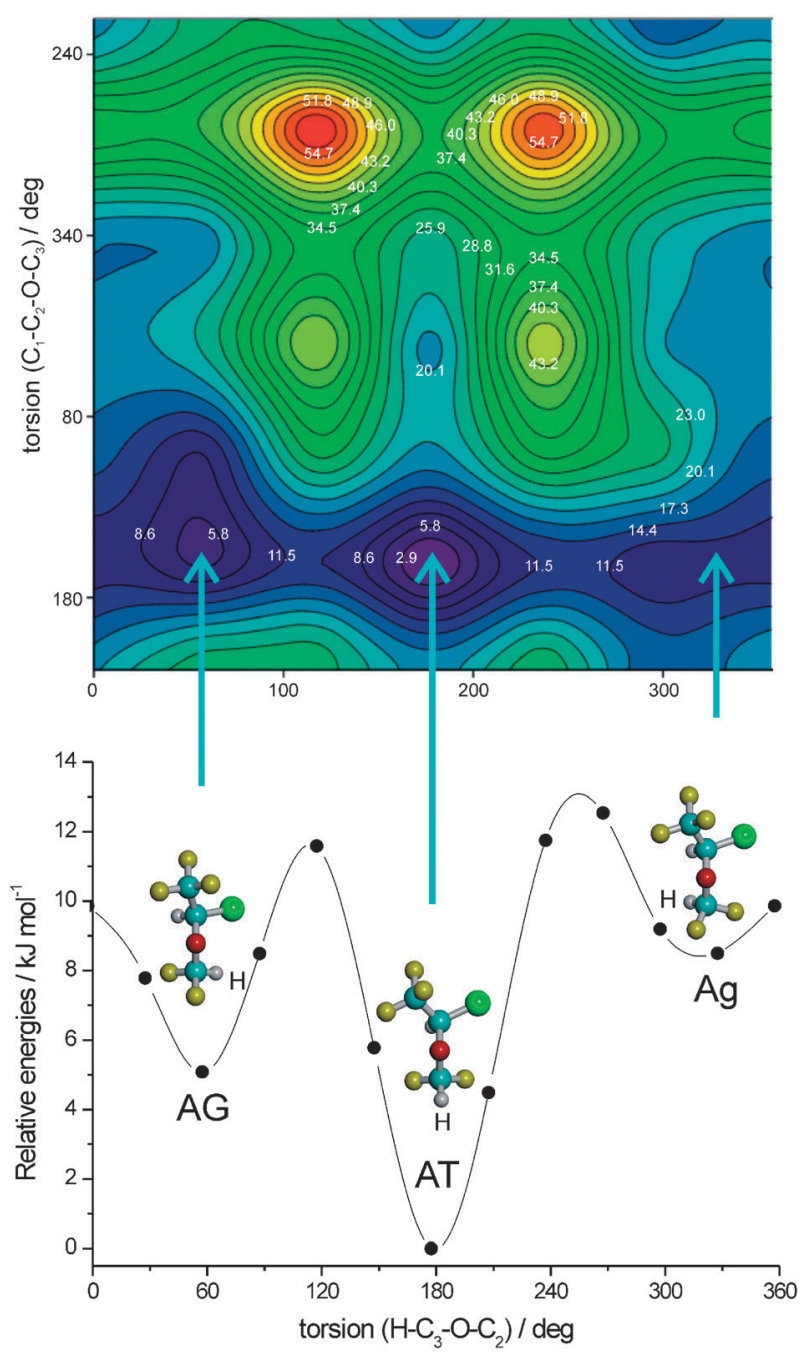

Fig. 4 Potential energy surface of isoflurane (B3LYP/6-311++ $\left.\mathrm{G}(2 \mathrm{df}, \mathrm{p}), \mathrm{kJ} \mathrm{mol}^{-1}\right)$.
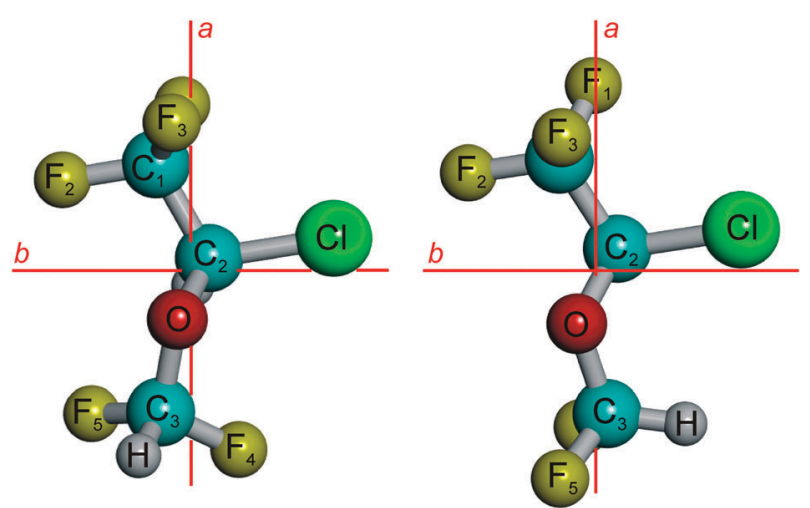

Fig. 5 Atom labeling and principal inertial axis system for the two most stable conformations of isoflurane (AT left; AG right).

\section{c Molecular structure}

The structure of isoflurane was derived from the rotational data in Tables 1 and 2. We calculated initially the atomic substitution coordinates $\left(r_{\mathrm{s}}\right)$ in the principal inertial axis for the isotopic species of conformers AT $\left(\mathrm{Cl}, \mathrm{C}_{1}, \mathrm{C}_{3}\right)$ and $\mathrm{AG}(\mathrm{Cl})$, using the 
Kraitchman equations ${ }^{15,21}$ and Costain's error estimates. ${ }^{22}$ In this calculation two small coordinates close to the $c$ principal inertial axes were imaginary and constrained to zero. The comparison in Table S7 (ESI $\dagger$ ) between the substitution and the atomic coordinates predicted $a b$ initio definitively confirmed the conformational assignments of the previous section.

An effective $\left(r_{0}\right)$ structure was calculated fitting the set of rotational constants of isoflurane AT and AG to different sets of structural parameters of the two conformers. In the fit of Table 4 three valence angles $\left(\left(\mathrm{C}_{1}-\mathrm{C}_{2}-\mathrm{O}\right), \quad\left(\mathrm{C}_{2}-\mathrm{O}-\mathrm{C}_{3}\right)\right.$, $\left.\left(\mathrm{Cl}-\mathrm{C}_{2}-\mathrm{O}\right)\right)$ and two dihedrals $\left(\left(\mathrm{C}_{1}-\mathrm{C}_{2}-\mathrm{O}-\mathrm{C}_{3}\right),\left(\mathrm{Cl}-\mathrm{C}_{2}-\mathrm{O}-\mathrm{C}_{3}\right)\right)$ defining the molecular skeleton were determined for isoflurane AT. A similar fit floating two valence angles $\left(\left(\mathrm{C}_{1}-\mathrm{C}_{2}-\mathrm{O}\right)\right.$, $\left.\left(\mathrm{Cl}-\mathrm{C}_{2}-\mathrm{O}\right)\right)$ and the same dihedrals is presented for isoflurane AG. Bond lengths were found not determinable from the available isotopic data. The positions of the monoisotopic fluorine atoms and those of the hydrogen atoms were kept fixed to the $a b$ initio values. The gas electron diffraction data $\left(r_{\mathrm{a}}\right)$, which determined only the lowest-energy structure AT, are given for comparison.

\section{Discussion}

The intrinsic structural properties of isoflurane have been probed in the isolation conditions of a supersonic expansion. The analysis of the rotational spectrum revealed two different conformations for the jet-cooled molecule, for which we determined accurate rotational and nuclear quadrupole hyperfine parameters. The absence of internal rotation tunnelling effects in the trifluoromethyl group is consistent with its larger moment of inertia, requiring observations in torsionally excited states. ${ }^{5,23}$ The conformational assignment of isoflurane was unequivocal on the basis of the isotopic data and the theoretical models derived $a b$ initio. Both the substitution coordinates and the comparison of the rotational constants and nuclear quadrupole coupling parameters with the theoretical values revealed that the two most stable structures of isoflurane correspond to conformations AT and AG in Fig. 5. The experimental preference of isoflurane for the predicted global minimum AT was established from relative intensity measurements, which yield jet population ratios of $N_{\mathrm{AT}} / N_{\mathrm{AG}} \approx 3$. The conformational landscape and the feasibility of other stable molecular conformations were investigated using the bidimensional ab initio PES of Fig. 4. The observed species AT and AG correlate with the two most stable species in the PES, but the $a b$ initio data apparently suggest the possibility of a third stable conformation Ag. In order to explain the jet-cooled abundances we considered how equilibrium populations evolve kinetically in the expansion. Conformational populations may be particularly affected by collisional relaxations transferring population to lower energy species, so the supersonic expansion will preserve the preexisting equilibrium conformational distribution only in the cases of large interconversion barriers. The relaxation barriers in Fig. 4 between the Ag and the AG or AT conformers are predicted to be 1.4 and $4 \mathrm{~kJ}$ $\mathrm{mol}^{-1}$, lower than the empirical threshold barriers proposed for a single torsional degree of freedom $\left(>4.8 \mathrm{~kJ} \mathrm{~mol}^{-1}\right){ }^{24} \mathrm{In}$ consequence we conclude that conformation $\mathrm{Ag}$ cannot be detected because of its conformational relaxation to the second most stable species AG.

Table 4 Effective structures $\left(r_{0}\right)$ of isoflurane AT and AG, and comparison with the ab initio $\left(r_{\mathrm{e}}\right)$ and GED data $\left(r_{\mathrm{a}}\right)$

\begin{tabular}{|c|c|c|c|c|c|}
\hline & \multicolumn{3}{|c|}{ Conformer AT } & \multicolumn{2}{|c|}{ Conformer AG } \\
\hline & $r_{0}$ & $\begin{array}{l}\text { Ab } \text { initio }^{a} \\
r_{\mathrm{e}}\end{array}$ & $r_{\mathrm{a}}^{b}$ & $r_{0}$ & $\begin{array}{l}\text { Ab initio } \\
r_{\mathrm{e}}\end{array}$ \\
\hline$r\left(\mathrm{C}_{1}-\mathrm{F}_{1}\right)^{c} / \AA$ & & 1.332 & $1.332(3)$ & & 1.332 \\
\hline$r\left(\mathrm{C}_{1}-\mathrm{F}_{2}\right) / \AA$ & & 1.334 & $1.332(3)$ & & 1.333 \\
\hline$r\left(\mathrm{C}_{1}-\mathrm{F}_{3}\right) / \AA$ & & 1.327 & $1.332(3)$ & & 1.326 \\
\hline$r\left(\mathrm{C}_{1}-\mathrm{C}_{2}\right) / \AA$ & & 1.526 & $1.536(11)$ & & 1.526 \\
\hline$r\left(\mathrm{C}_{2}-\mathrm{Cl}\right) / \AA$ & & 1.767 & $1.773(8)$ & & 1.780 \\
\hline$r\left(\mathrm{C}_{2}-\mathrm{O}\right) / \AA$ & & 1.399 & $1.401(15)$ & & 1.387 \\
\hline$r\left(\mathrm{C}_{3}-\mathrm{O}\right) / \AA$ & & 1.368 & & & 1.379 \\
\hline$r\left(\mathrm{C}_{3}-\mathrm{F}_{4}\right) / \AA$ & & 1.348 & & & 1.353 \\
\hline$r\left(\mathrm{C}_{3}-\mathrm{F}_{5}\right) / \AA$ & & 1.351 & & & 1.329 \\
\hline$\angle\left(\mathrm{C}_{1}-\mathrm{C}_{2}-\mathrm{O}\right) /^{\circ}$ & $106.7(10)^{d}$ & 106.6 & $108.5(19)$ & $107.8(10)$ & 106.2 \\
\hline$\angle\left(\mathrm{C}_{2}-\mathrm{O}-\mathrm{C}_{3}\right) /^{\circ}$ & $116.7(4)$ & 115.2 & $113.4(28)$ & & 114.7 \\
\hline$\angle\left(\mathrm{Cl}-\mathrm{C}_{2}-\mathrm{O}\right) /^{\circ}$ & $112.5(10)$ & 111.6 & & $113.9(8)$ & 112.5 \\
\hline$\angle\left(\mathrm{C}_{2}-\mathrm{C}_{1}-\mathrm{F}_{1}\right) /^{\circ}$ & & 110.4 & & & 110.0 \\
\hline$\left.\angle\left(\mathrm{C}_{2}-\mathrm{C}_{1}-\mathrm{F}_{2}\right)\right|^{\circ}$ & & 109.1 & & & 109.2 \\
\hline$\angle\left(\mathrm{C}_{2}-\mathrm{C}_{1}-\mathrm{F}_{3}\right) /^{\circ}$ & & 111.8 & & & 111.8 \\
\hline$\left.\angle\left(\mathrm{O}-\mathrm{C}_{3}-\mathrm{F}_{4}\right)\right|^{\circ}$ & & 111.3 & & & 106.2 \\
\hline$\angle\left(\mathrm{O}-\mathrm{C}_{3}-\mathrm{F}_{5}\right) /^{\circ}$ & & 110.8 & & & 110.0 \\
\hline$\tau\left(\mathrm{C}_{1}-\mathrm{C}_{2}-\mathrm{O}-\mathrm{C}_{3}\right) /^{\circ}$ & $137.8(11)$ & 138.1 & $136(5)$ & $167.4(19)$ & 167.8 \\
\hline$\tau\left(\mathrm{Cl}-\mathrm{C}_{2}-\mathrm{O}-\mathrm{C}_{3}\right) /^{\circ}$ & $-101.5(11)$ & -102.1 & & $-69.8(14)$ & -72.3 \\
\hline$\tau\left(\mathrm{F}_{1}-\mathrm{C}_{1}-\mathrm{C}_{2}-\mathrm{O}\right) /^{\circ}$ & & -179.9 & & & -179.5 \\
\hline$\tau\left(\mathrm{F}_{2}-\mathrm{C}_{1}-\mathrm{C}_{2}-\mathrm{O}\right){ }^{\circ}$ & & -61.2 & & & -60.9 \\
\hline$\tau\left(\mathrm{F}_{3}-\mathrm{C}_{1}-\mathrm{C}_{2}-\mathrm{O}\right) /^{\circ}$ & & 58.8 & & & 59.4 \\
\hline$\left.\tau\left(\mathrm{F}_{4}-\mathrm{C}_{3}-\mathrm{O}-\mathrm{C}_{2}\right)\right|^{\circ}$ & & 56.1 & & & -62.1 \\
\hline$\tau\left(\mathrm{F}_{5}-\mathrm{C}_{3}-\mathrm{O}-\mathrm{C}_{2}\right) /^{\circ}$ & & -61.9 & & & -179.3 \\
\hline$\tau\left(\mathrm{C}_{2}-\mathrm{O}-\mathrm{C}_{3}-\mathrm{H}\right) /^{\circ}$ & & 177.4 & $170(9)$ & & 59.3 \\
\hline
\end{tabular}


The structural properties of isoflurane were determined independently for the AT and AG conformers from the rotational parameters of six different carbon and chlorine isotopic species. The two detected conformers differ in the orientation of the difluoromethyl group (trans or gauche $\mathrm{C}_{2}-\mathrm{O}-\mathrm{C}_{3}-\mathrm{H}$ for the global minimum and the second most stable species, respectively) but there are also significant differences in the orientation of the trifluoromethyl and the chlorine atom, which change $\sim 30^{\circ}$ between the global minimum AT $\left(\mathrm{C}_{1}-\mathrm{C}_{2}-\mathrm{O}-\mathrm{C}_{3}=137.8(11), \mathrm{Cl}-\mathrm{C}_{2}-\mathrm{O}-\mathrm{C}_{3}=\right.$ $-101.5(11))$ and conformer $\mathrm{AG}\left(\mathrm{C}_{1}-\mathrm{C}_{2}-\mathrm{O}-\mathrm{C}_{3}=167.4(19)\right.$, $\left.\mathrm{Cl}-\mathrm{C}_{2}-\mathrm{O}-\mathrm{C}_{3}=-69.8(14)\right)$. The anti orientation of the carbon skeleton in isoflurane is particularly different from the trans conformations of the aliphatic prototype ethyl methyl ether ${ }^{25}$ and related ethers like the constitutional isomer enflurane. ${ }^{26}$ The origin of the structural preferences of isoflurane has been attributed to a combination of anomeric and steric effects. ${ }^{10} \mathrm{In}$ this view the gauche orientation of the difluoromethyl $\mathrm{C}-\mathrm{F}$ bonds would result from the $\mathrm{n}_{\mathrm{O}}-\sigma^{*} \mathrm{CF}$ orbital interaction between the electron lone pairs at the oxygen atom $\left(\mathrm{n}_{\mathrm{O}}\right)$ and the two $\mathrm{C}-\mathrm{F}$ antibonding orbitals $\left(\sigma^{*} \mathrm{CF}\right)$. In this orientation the $\mathrm{C}-\mathrm{F}$ bonds are trans to the oxygen lone pairs, maximizing the hyperconjugative interaction. ${ }^{27}$ As a secondary effect the eclipsing orientation of the $\mathrm{C}_{3}-\mathrm{F}_{4}$ and the $\mathrm{C}_{2}-\mathrm{Cl}$ bond would be impeded sterically, forcing a torsion of the trifluoromethyl group. We tested these hypotheses using structural and molecular orbital arguments. The presence of hyperconjugative interactions would be associated to several structural effects, including a shortening of the $\mathrm{O}-\mathrm{C}_{\mathrm{F}}$ bond, a lengthening of the $\mathrm{C}-\mathrm{F}$ bond and an increase of the $\mathrm{O}-\mathrm{C}_{\mathrm{F}}-\mathrm{F}$ valence angle, as observed in other fluorinated derivatives. ${ }^{5,28,29}$ For isoflurane the bond lengths could not be determined experimentally, so we compared the $a b$ initio predictions in Table 4 with those for sevoflurane $(r(\mathrm{C}-\mathrm{O})=1.389 / 1.403 \AA),{ }^{5}$ enflurane $(r(\mathrm{C}-\mathrm{O})=$ $1.357 / 1.389 \AA)$ and ethyl methyl ether $(r(\mathrm{C}-\mathrm{O})=1.409 / 1.413 \AA)$ in Table S8 (ESI $\dagger)$. The carbon-oxygen bond lengths in isoflurane AT are consistent with the presence of hyperconjugation, since they differ by $0.031 \AA$ and the shorter $r\left(\mathrm{C}_{3}-\mathrm{O}\right)=$ $1.368 \AA$ bond is comparable to that in fluoromethyl methyl ether. ${ }^{28}$ On the other hand the two gauche difluoromethyl $\mathrm{CF}$ bond lengths $\left(r\left(\mathrm{C}_{3}-\mathrm{F}_{4}\right)=1.348 \AA\right.$ and $\left.r\left(\mathrm{C}_{3}-\mathrm{F}_{5}\right)=1.351 \AA\right)$ appear very similar and only slightly larger than the values in the trifluoromethyl group (1.327-1.334 $\AA$ ). For isoflurane GT the difference between the two $\mathrm{C}-\mathrm{O}$ bonds is much smaller $(0.008 \AA)$, but at the same time the gauche $\mathrm{C}_{3}-\mathrm{F}_{4}$ bond length $(1.353 \AA)$ is larger than the trans $\mathrm{C}_{3}-\mathrm{F}_{5}$ bond $(1.329 \AA)$. Both facts point to a different distribution of hyperconjugative effects in the two conformations. At the same time the carbon-chlorine distances in isoflurane (AT: $r\left(\mathrm{C}_{2}-\mathrm{Cl}\right)=$ $1.767 \AA$; $\mathrm{AG}: r\left(\mathrm{C}_{2}-\mathrm{Cl}\right)=1.780 \AA$ ) are larger than in enflurane (Table S8: $r\left(\mathrm{C}_{1}-\mathrm{Cl}\right)=1.753 \AA$ ), suggesting that the orientation of the chlorine atom could be due also to orbital interactions. A comparison with desflurane, ${ }^{30}$ where chlorine is replaced by a fluorine atom and the steric repulsions would be smaller, supports this argument since the molecular skeleton displays a similar torsion as in isoflurane $\left(\tau\left(\mathrm{C}_{1}-\mathrm{C}_{2}-\mathrm{O}-\mathrm{C}_{3}\right)=145.4^{\circ}\right)$.

In order to estimate quantitatively the magnitude of the plausible donor-acceptor hyperconjugative interactions in isoflurane we conducted NBO analyses for the two most stable conformations. In the NBO analysis, the electronic wavefunctions are interpreted in terms of a set of occupied Lewis and a set of unoccupied non-Lewis localized orbitals. The delocalization effects (or donor-acceptor charge transfers) can be estimated from the presence of off-diagonal elements of the Fock matrix in the NBO basis. The NBO program searches for an optimal natural Lewis structure, which has the maximum occupancy of its occupied NBOs, and in general agrees with the pattern of bonds and lone pairs of the standard structural Lewis formula. Therefore, the new orbitals are more stable than pure Lewis orbitals, stabilizing the wave function and giving a set of molecular orbitals equivalent to canonical molecular orbitals.

The results of the NBO calculations shown in Scheme 1 and Table 5 confirm that both the AT and AG conformations of isoflurane benefit strongly from donor-acceptor electron delocalizations. However, the most important hyperconjugative interactions in isoflurane involve not only the fluorine atoms, but also the oxygen electron lone pair and the vicinal $\mathrm{C}-\mathrm{Cl}$ antibonding orbital, with $\mathrm{LP}_{2} \mathrm{O} \rightarrow \sigma^{*}{ }_{\mathrm{C} 2-\mathrm{Cl}}$ electron delocalizations for the AT and AG conformations of 56.4 and $68.9 \mathrm{~kJ} \mathrm{~mol}^{-1}$, respectively. The total contribution of the generalized anomeric effect (GAE) to the equilibrium between
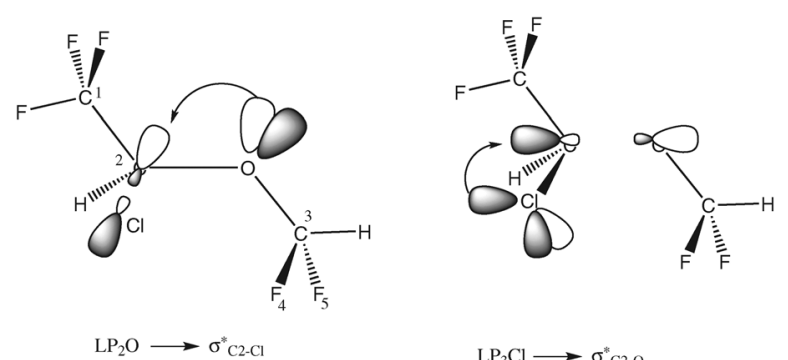

$\mathrm{LP}_{3} \mathrm{Cl} \longrightarrow \sigma^{*}{ }^{2}-\mathrm{O}$
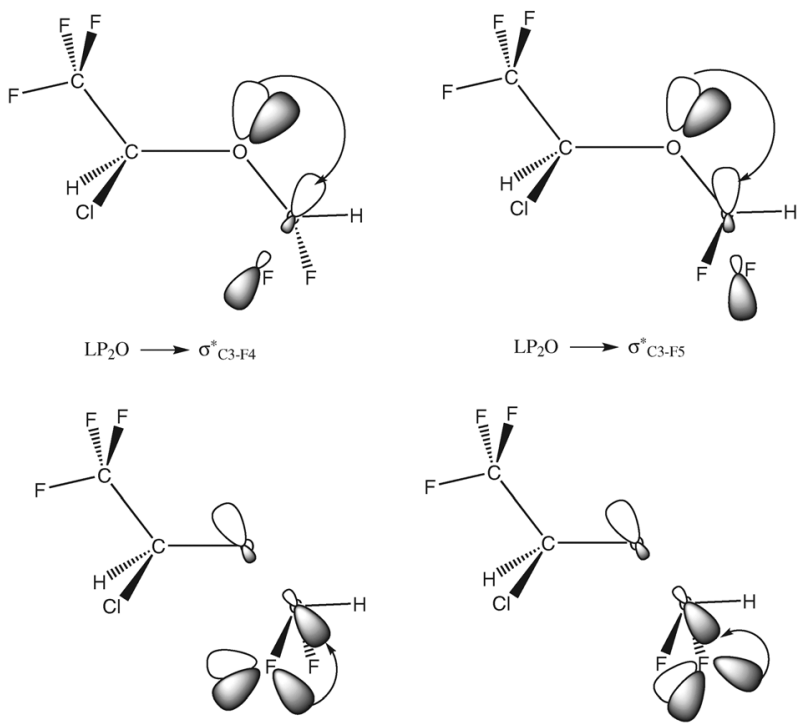

$\mathrm{LP}_{3} \mathrm{~F}_{4} \longrightarrow \sigma_{\mathrm{C} 3-\mathrm{O}}^{*}$

$\mathrm{LP}_{3} \mathrm{~F}_{5} \longrightarrow \sigma_{\mathrm{C} 3-\mathrm{O}}^{*}$

Scheme 1 Schematic representations of the electron delocalization between non-bonding and anti-bonding orbitals in the two most stable conformations of isoflurane according to the NBO results (NBOB3LYP/6-311++G(d,p)). 
Table 5 NBO-B3LYP/6-311++G(d,p) stabilization energies $\left(E_{2}\right)$, donor-acceptor orbital energy differences $\left(\Delta E_{i j}\right)$, off-diagonal elements $\left(F_{i j}\right)$ and bond orders (Wiberg Bond Index, WBI) for the AT and AG conformations of isoflurane (all energies in $\mathrm{kJ} \mathrm{mol}^{-1}$ )

\begin{tabular}{|c|c|c|c|c|c|c|}
\hline & \multicolumn{3}{|l|}{ AT } & \multicolumn{3}{|l|}{$\mathrm{AG}$} \\
\hline & $E_{2}$ & $\Delta E_{i j}$ & $F_{i j}$ & $E_{2}$ & $\Delta E_{i j}$ & $F_{i j}$ \\
\hline $\mathrm{LP}_{1} \mathrm{O} \rightarrow \sigma^{*} 2-\mathrm{Cl}$ & - & - & - & 3.4 & 1759.1 & 55.1 \\
\hline $\mathrm{LP}_{2} \mathrm{O} \rightarrow \sigma^{*}{ }_{2}-\mathrm{Cl}$ & 56.4 & 1155.2 & 183.8 & 68.9 & 1102.7 & 199.5 \\
\hline $\mathrm{LP}_{2} \mathrm{Cl} \rightarrow \sigma^{*}{ }_{\mathrm{C} 2-\mathrm{O}}$ & 2.3 & 1496.5 & 42.0 & 4.1 & 1549.1 & 57.8 \\
\hline $\mathrm{LP}_{3} \mathrm{Cl} \rightarrow \sigma^{*}{ }_{\mathrm{C} 2-\mathrm{O}}$ & 35.7 & 1470.3 & 162.8 & 30.4 & 1549.1 & 154.9 \\
\hline $\mathrm{LP}_{1} \mathrm{O} \rightarrow \sigma^{*}{ }^{*} 3-\mathrm{F} 4$ & 7.6 & 2126.7 & 91.9 & 8.1 & 2126.7 & 94.5 \\
\hline $\mathrm{LP}_{1} \mathrm{O} \rightarrow \sigma^{*}{ }_{\mathrm{C} 3-\mathrm{F} 5}$ & 9.3 & 2126.7 & 99.8 & 22.9 & 2231.7 & 160.2 \\
\hline $\mathrm{LP}_{2} \mathrm{O} \rightarrow \sigma^{*}{ }_{\mathrm{C} 3-\mathrm{F} 4}$ & 52.8 & 1496.5 & 149.7 & 51.0 & 1496.5 & 196.9 \\
\hline $\mathrm{LP}_{2} \mathrm{O} \rightarrow \sigma^{*}{ }^{*} 3-\mathrm{F} 5$ & 51.9 & 1470.3 & 199.5 & - & - & - \\
\hline $\mathrm{LP}_{2} \mathrm{~F}_{4} \rightarrow \sigma^{*}{ }^{*}-\mathrm{O}$ & 31.1 & 1890.4 & 173.3 & 23.3 & 1864.1 & 147.0 \\
\hline $\mathrm{LP}_{3} \mathrm{~F}_{4} \rightarrow \sigma^{*}{ }^{*}-\mathrm{O}$ & 17.9 & 1890.4 & 131.3 & 23.8 & 1864.1 & 149.7 \\
\hline $\mathrm{LP}_{2} \mathrm{~F}_{5} \rightarrow \sigma^{*}{ }^{*}-\mathrm{O}$ & 26.8 & 1890.4 & 160.2 & 28.5 & 1864.1 & 162.8 \\
\hline $\mathrm{LP}_{3} \mathrm{~F}_{5} \rightarrow \sigma^{*}{ }^{*}-\mathrm{O}$ & 20.4 & 1890.4 & 139.2 & 19.8 & 1864.1 & 136.5 \\
\hline$\Sigma$ & 312.1 & & & 282.3 & & \\
\hline GAE & -29.8 & & & & & \\
\hline \multicolumn{7}{|c|}{ Wiberg Bond Index (WBI) } \\
\hline $\mathrm{C}_{2}-\mathrm{O}$ & & 0.9188 & & & 0.9466 & \\
\hline $\mathrm{C}_{2}-\mathrm{Cl}$ & & 1.0149 & & & 0.9903 & \\
\hline $\mathrm{C}_{3}-\mathrm{O}$ & & 0.9614 & & & 0.9274 & \\
\hline
\end{tabular}

the AT and AG conformations including all $\mathrm{LPO} \rightarrow \sigma^{*}{ }_{\mathrm{C} 2-\mathrm{Cl}}$, $\mathrm{LPCl} \rightarrow \sigma^{*}{ }_{\mathrm{C} 2-\mathrm{O}}$, LPO $\rightarrow \sigma^{*}{ }_{\mathrm{C} 3-\mathrm{CF}}$, and $\mathrm{LPF} \rightarrow \sigma^{*}{ }_{\mathrm{C} 3-\mathrm{O}}$ electronic delocalizations was calculated in Table 5 as GAE $=$ $\Sigma\left(\mathrm{GAE}_{\mathrm{AG}}\right)-\Sigma\left(\mathrm{GAE}_{\mathrm{AT}}\right)=-29.8 \mathrm{~kJ} \mathrm{~mol}^{-1}$. The decrease in the value of the GAE from the AT to the AG conformation is shown to be the major cause for the AT conformational preference of isoflurane.

There is also a preference for the conformation with the smallest resultant dipole moment. Especially in the gas phase it is generally found that the conformation with the larger dipole moment has the larger electrostatic energy and therefore an increased overall energy. Table 3 presents the MP2/ $6-311++\mathrm{G}(2 \mathrm{df}, \mathrm{p})$ calculated dipole moments for the AT and AG conformations. The results, while the interpretation is only qualitative, show that the dipole moment increase from the AT conformation to the AG conformation is an added factor for the greater stability of the AT conformation.

It should be remembered that the calculated GAE value associated with electron delocalization $\left(-29.8 \mathrm{~kJ} \mathrm{~mol}^{-1}\right)$ is not the energy difference between the AT and AG conformations, but rather represents the major impact on the conformational preference for the AT form. Besides the GAE, steric repulsions have an impact on the conformational behavior. Based on the structures of the AT and AG conformations, it appears that the steric repulsions between the $\mathrm{Cl}$ atom attached to $\mathrm{C}_{2}$ and the $\mathrm{F}_{4}$ atom attached to $\mathrm{C}_{3}$ may reduce the stability of the AT conformation compared to the AG conformation. However, the total energy difference between the AT and AG conformations (i.e. $\sim 2 \mathrm{~kJ} \mathrm{~mol}^{-1}$ in Table 3 ) is due to the sum of the effects resulting from the GAE, the steric effects and dipole-dipole interactions.

The electron delocalizations can be correlated to structural effects through the bond orders (Wiberg Bond Index, WBI: sum of squares of off-diagonal density matrix elements between atoms, as formulated in terms of the natural atomic orbital (NAO) basis set). The greater $\mathrm{LP}_{2} \mathrm{O} \rightarrow \sigma^{*}{ }_{\mathrm{C} 2-\mathrm{Cl}}$ electron delocalization increases the bond order in $\mathrm{C}_{2}-\mathrm{O}$ (0.919 and 0.947, respectively, in AT and AG) while decreasing in $\mathrm{C}_{2}-\mathrm{Cl}$ (1.015 and 0.990 , respectively). Therefore, the different bond orders reasonably explain the shorter $\mathrm{C}_{2}-\mathrm{O}$ and longer $\mathrm{C}_{2}-\mathrm{Cl}$ bond lengths in the $\mathrm{AG}$ conformation compared to the AT. There is no $\mathrm{LP}_{2} \mathrm{O} \rightarrow \sigma^{*}{ }^{*} 3-\mathrm{F} 5$ electron delocalization for the AG conformation, justifying the smaller $\mathrm{C}_{3}-\mathrm{O}$ bond length and associated greater bond order for this bond in the AT conformation.

This work emphasizes the use of modern rotational techniques for structural studies and the relevance of stereoelectronic effects in molecular conformation. The combination of rotational data with $a b$ initio calculations provides a detailed description of the isolated molecule which may be useful for the molecular modeling of this anesthetic. The availability of spectroscopic data will also allow the study of weakly-bound intermolecular complexes or hydration aggregates involving isoflurane. Other rotational studies of anesthetic ethers will be presented in following publications.

\section{Acknowledgements}

We thank the Deutsche Forschungsgemeinschaft (DFG), the Land Niedersachsen, the Spanish ministry of science MICINN (CTQ2009-14364-C02-02) and the JCyL (VA017A08) for financial support. R.S. and D.J.B. thank Jerry Fraser at NIST for experimental resources. A.V.-T. acknowledges support from a FPU doctoral grant. The work at the University of Texas has been supported by grant F-100 from the Welch Foundation.

\section{References}

1 N. P. Franks and W. R. Lieb, Nature, 1994, 367, 607.

2 A. S. Evers, C. M. Crowder and J. R. Balser, in Goodman \& Gilman's The Pharmacological Basis of Therapeutics, ed. L. L. Brunton, 
J. S. Lazo and K. L. Parker, McGraw-Hill, New York, 2006, 11th edn, ch. 13.

3 A. A. Bhattacharya, S. Curry and N. P. Franks, J. Biol. Chem., 2000, 275, 38731 .

4 E. J. Bertaccini, J. R. Trudell and N. P. Franks, Anesthetic Pharm., 2007, 104, 318.

5 A. Lesarri, A. Vega-Toribio, R. Suenram, D. J. Brugh and J.-U. Grabow, Phys. Chem. Chem. Phys., 2010, 12, 9624.

6 A. Lesarri, S. T. Shipman, J. L. Neill, G. G. Brown, R. D. Suenram, L. Kang, W. Caminati and B. H. Pate, J. Am. Chem. Soc., 2010, 132, 13417.

7 G. S. Lysko, J. L. Robinson, R. Casto and R. A. Ferrone, Eur. J. Pharmacol., 1994, 263, 25.

8 (a) P. L. Polavarapu, A. L. Cholli and G. Vernice, J. Am. Chem. Soc., 1992, 114, 10953; (b) P. L. Polavarapu, A. L. Cholli and G. Vernice, J. Pharm. Sci., 1993, 82, 791; (c) P. L. Polavarapu, A. L. Cholli and G. Vernice, J. Pharm. Sci., 1997, 35, 1680.

9 V. Schurig, M. Juza, B. S. Green, J. Horakh and A. Simon, Angew. Chem., Int. Ed., 1996, 35, 1680.

10 A. Hermann, H.-G. Mack and H. Oberhammer, J. Fluorine Chem., 2000, 101, 223.

11 (a) F. J. Lovas and R. D. Suenram, J. Chem. Phys., 1987, 87, 2010; (b) R. D. Suenram, J.-U. Grabow, A. Zuban and I. Leonov, Rev. Sci. Instrum., 1999, 70, 2127.

12 (a) J.-U. Grabow and W. Stahl, Z. Naturforsch., A: Phys. Sci., 1990, 45, 1043; (b) J.-U. Grabow, W. Stahl and H. Dreizler, Rev. Sci. Instrum., 1996, 67, 4072.

13 T. J. Balle and W. H. Flygare, Rev. Sci. Instrum., 1981, 52, 33.

14 M. J. Frisch, et al., Gaussian03, Gaussian Inc, Pittsburgh PA, 2003.

15 W. Gordy and R. L. Cook, Microwave Molecular Spectra, Wiley, New York, 1984.

16 J. K. Watson, in Vibrational Spectra and Structure, ed. J. R. Durig, Elsevier, Amsterdam, 1977, vol. 6, pp. 1-89.
17 H. M. Pickett, J. Mol. Spectrosc., 1991, 148, 371.

18 J. M. Fischer, L.-H. Xu, R. D. Suenram, B. H. Pate and K. Douglass, J. Mol. Struct., 2006, 795, 143.

19 G. T. Fraser, R. D. Suenram and C. L. Lugez, J. Phys. Chem. A, $2000,104,1141$.

20 S. Blanco, A. Lesarri, J. C. López and J. L. Alonso, J. Am. Chem. Soc., 2004, 126, 11675.

21 H. D. Rudolph, in Advances in Molecular Structure Research, ed. M. Hargittai and I. Hargittai, JAI Press, Greenwich-Connecticut, 1995, vol. 1, ch. 3, pp. 63-114.

22 (a) B. P. van Eijck, J. Mol. Spectrosc., 1982, 91, 348; (b) C. C. Costain, Trans. Am. Crystallogr. Assoc., 1966, 2, 157.

23 J. L. Alonso, A. Lesarri, J. C. López, S. Blanco, I. Kleiner and J. Demaison, Mol. Phys., 1997, 91, 731.

24 (a) P. D. Godfrey and R. D. Brown, J. Am. Chem. Soc., 1998, 120 , 10724; (b) R. S. Ruoff, T. D. Klots, T. Emilsson and H. S. Gutowsky, J. Chem. Phys., 1990, 93, 3142.

25 (a) J. R. Durig, Y. Jin, H. V. Phan, J. Liu and D. T. Durig, Struct. Chem., 2002, 13, 1; (b) M. Hayashi and M. Adachi, J. Mol. Struct., $1970,6,457$

26 (a) A. Lesarri, A. Vega-Toribio, R. Suenram, D. J. Brugh, J.-U. Grabow, unpublished; (b) A. Pfeiffer, H.-G. Mack and H. Oberhammer, J. Am. Chem. Soc., 1998, 120, 6384.

27 (a) A. J. Kirby, The Anomeric Effect and Related Stereoelectronic Effects at Oxygen, Springer-Verlag, Berlin, 1983; (b) P. Deslongchamps, Stereoelectronic Effects in Organic Chemistry, Pergamon, Oxford, 1983; (c) I. V. Alabugin and T. A. Zeidan, J. Am. Chem. Soc., 2002, 124, 3175.

28 J. R. Durig, J. Liu, G. A. Guirgis and B. J. Van der Veken, Struct. Chem., 1993, 4, 103.

29 R. Kühn, D. Christen, H.-G. Mack, D. Konikowski, R. Minkwitz and H. Oberhammer, J. Mol. Struct., 1996, 376, 217.

30 R. D. Suenram, S. T. Shipman, B. H. Pate and G. G. Brown, 66th Int. Symp. Mol. Spectrosc., Columbus (OH), Comm. RH06, 2008. 